\title{
Tribological Mechanism in Chip Formation and Its Use to Improve Machining Process
}

Karol Vasilko

Faculty of Manufacturing Technologies, Technical University of Košice, 08001 Prešov, Bayerova 1, SR. M: karol.vasilko@tuke.sk

It is a well-known fact that during cutting there occurs an extremely high degree of chip plastic deformation. These deformation structures require attention as they influence technical and economical results of cutting (cutting forces, quality of machined surface, tool wear, cutting temperature). Intensive friction between the tool and the chip as well as inside the deformed chip trigger the mechanism of plastic deformation. The paper analyses the mechanism and suggests the possibilities of its use to influence the deformation field inside the chip with the aim to improve cutting process.

Keywords: machining, turning, plastic deformation, tool life, surface quality

\section{Introducion}

In Fig. 1 there is a typical metallographic thin section of the zone of chip formation when cutting carbon steel C45.

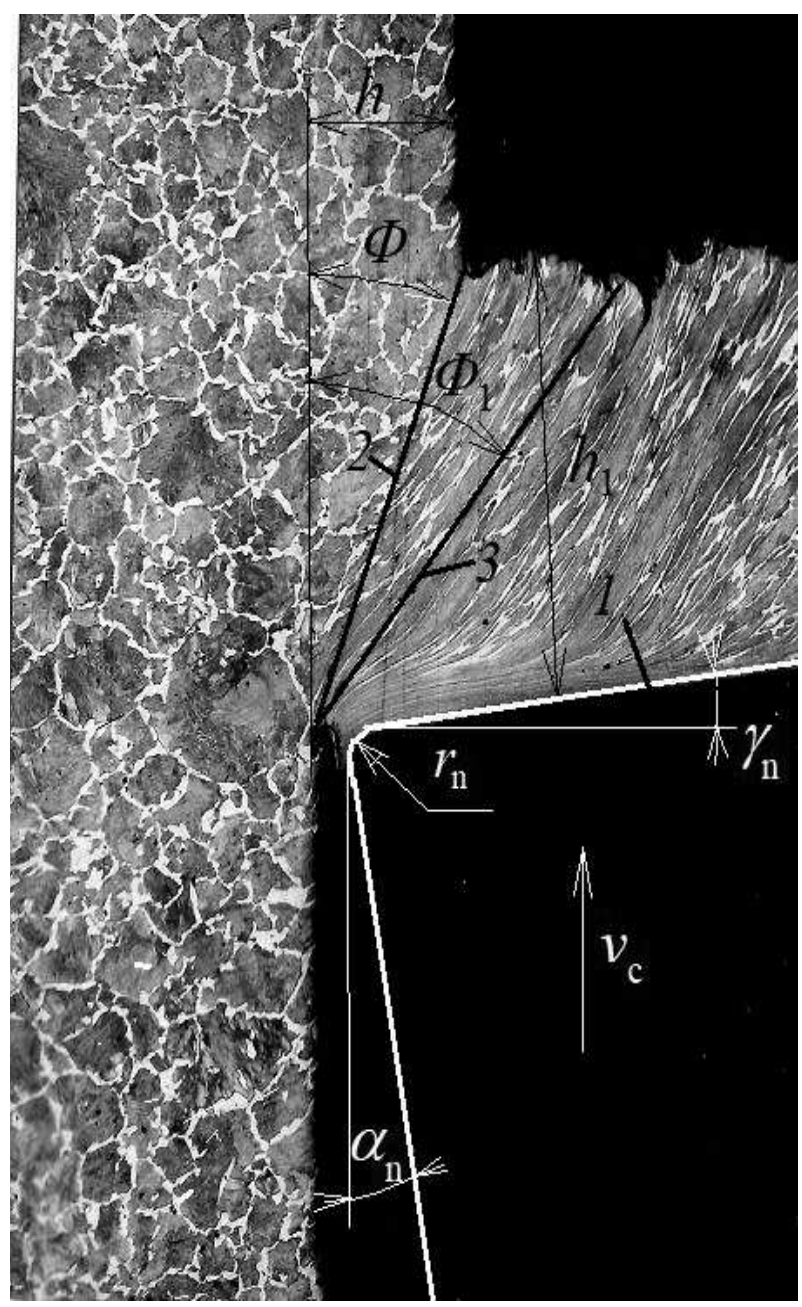

Fig. 1 Metallographic thin section of chip formation. Cut material C45, 1-external friction between the tool face and chip, 2 - intercristalline friction, 3 - internal cristalline friction. $\phi$ - angle of ,, slide plane“, $\phi_{1}$ - an-

gle of texture in chip. $\gamma_{\mathrm{n}}=-6^{0}, v_{c}=120 \mathrm{~m} \cdot \mathrm{min}^{-1}$
The chip remains in direct contact with the tool face and causes extreme pressure on the tool. Its movement is accompanied by intensive friction between the material of the tool and the chip, which leads to considerable forces and initiation of heat made by friction of both materials, at high pressure and temperature [1], [2], [3] ... This leads to tool wear. That is the reason why mechanic characteristics of the tool must be much better than the ones of the cut material. Curving of the grains of metal and formation of a narrow strip of fibre material, which are formed as a result of strong adhesion between the tool and cut materials [4], [5], [6], can be observed between the tool face and the chip.

In the zone of chip formation, three areas of friction can be characterised (Fig. 1):

Intensiveness of outer friction on the surface 1 depends on the size of friction coefficient between the cut and cutting materials. It is a source of heat which warms up the tool and the chip, it causes the decrease of hardness of tool cutting wedge and its wear on face. The friction along the slide line 2 , inclined under angle $\phi$ takes place primarily along grain borders, it takes place cold and is in fact the reason why the chip is formed in given configuration. The heat which is created there spreads into the chip and cut-off layer which changes into the chip. The friction along line 3 , oriented under texture angle $\phi_{1}$ takes place inside metal grains under the conditions of high temperature, probably with small coefficient of internal friction. The result is the texture of elongated metal grains in the chip and much larger thickness of chip $\mathrm{h}_{1}$ than the thickness of cut-off layer h. It can realistically be supposed that in this area, the cut material provides the least resistance against deformation. This fact leads to the suggestion to transfer the area of plastic deformation into the zone of internal friction in the grains of cut material. The next chapter presents the way into realistic form.

\section{Solution basics}

The solution is based on the modification of the tool geometry, see Fig. 2 [15]. A short tab is formed on the tool face under the negative face angle $\gamma_{n 1}$. Vice versa, a regular face angle $\gamma_{n 2}$ must be larger than the natural 
angle of the chip leaving, $\gamma_{\mathrm{nt}}$. It can be supposed that when the tap has suitable incline, a plastic layer of material is formed on it, just like in the case of a well-known built-up edge. This means that if the face angle is sufficiently large, the chip would slide along the ,plastic wedge"and its contact with the tool face would stop. Then there occurs a state when $\left.\gamma_{n 2}\right\rangle \gamma_{n t}$. Next, it can be considered that the shortened face tab, i.e. also plastic field in the chip, $w_{\mathrm{f}}$ would approximately equal the thickness of the cut-off layer $h$. To prove those thoughts, a range of experiments with such modified tools has been conducted.

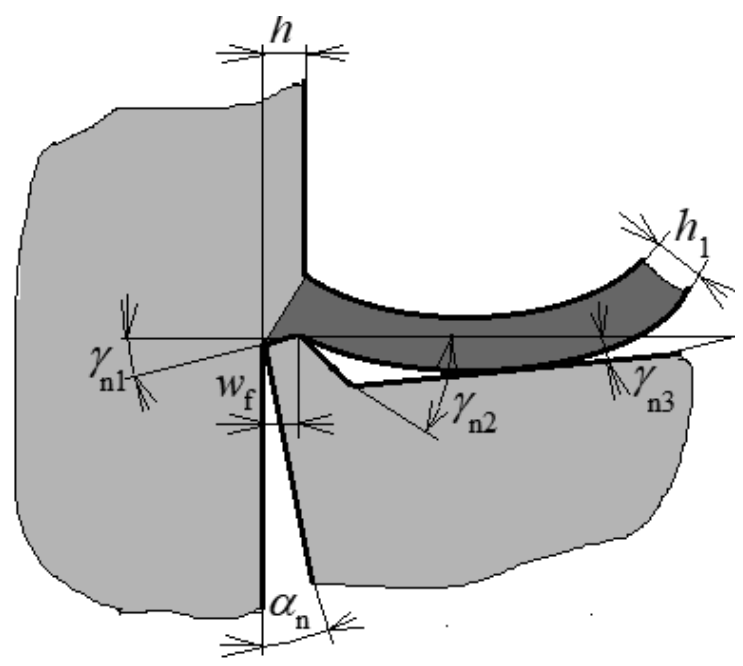

Fig. 2 Scheme of the interaction of the tool with modified geometry with workpiece

\section{New mechanism of chip formation}

The presented tool geometry enables free leaving of the chip. The chip compression is a little smaller than 1 , which is the reason why the formed chip is fluent. When cutting steel it is therefore important to create conditions for suitable chip shaping. This can be done by the modification of another face part, so after a short section with large face angle, the following face area is modified under the same angle as the shortened tab (in presented case it is $\left.-6^{0}\right)$. This is how ,flat shaper"of the chip is designed. The scheme of the movement of the chip along the tool face is shown in Fig. 3. The mechanism of shaping and breaking of the chip is the following: The chip leaves along the inclined face surface and bends along the straight face and is being pressed into the transfer area. As a result of this, it breaks in the suggested point. The photography shows that this mechanism does not allow to form more than 2-3 threads of the chip. The shape of the chip is the threaded spiral. Leaving of the chip is free, without any obstacles, the same as with stepped shapers, which is the reason why cutting force is not growing.

During the study of built-up edge phenomena and the mechanism of plastic deformation during chip formation, it has appeared that the plastic field can serve as a means of protection of the cutting tool against wear.
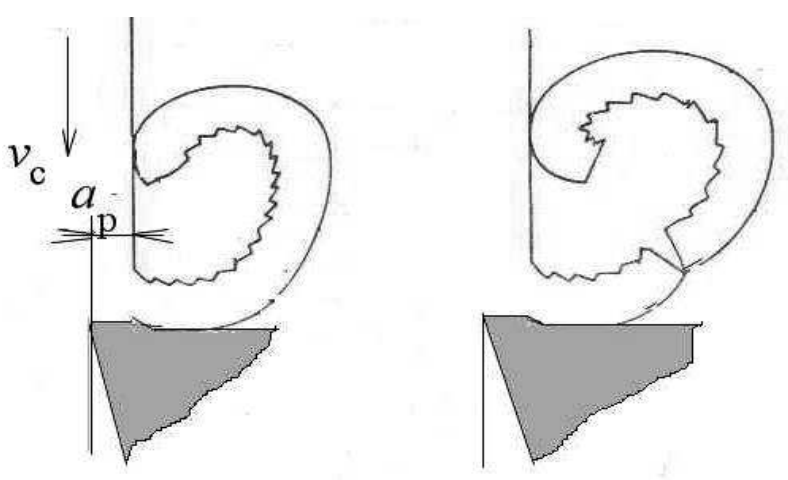

a)

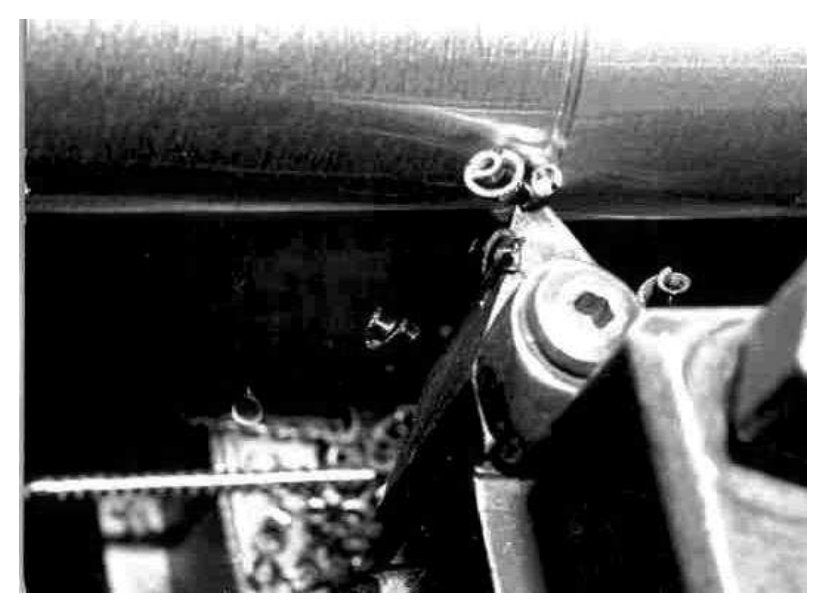

b)

Fig. 3 Shaping of the chip under the influence of ,flat shaper ". $a$-scheme, $b$-view of machining process

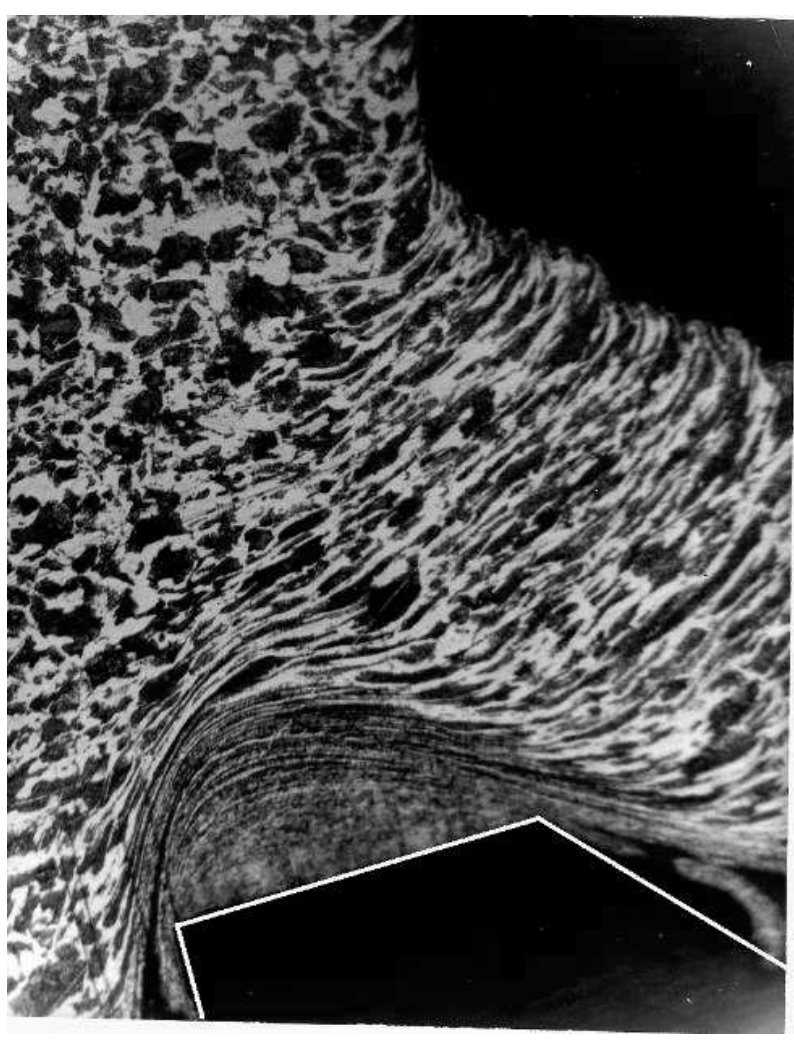

a) 


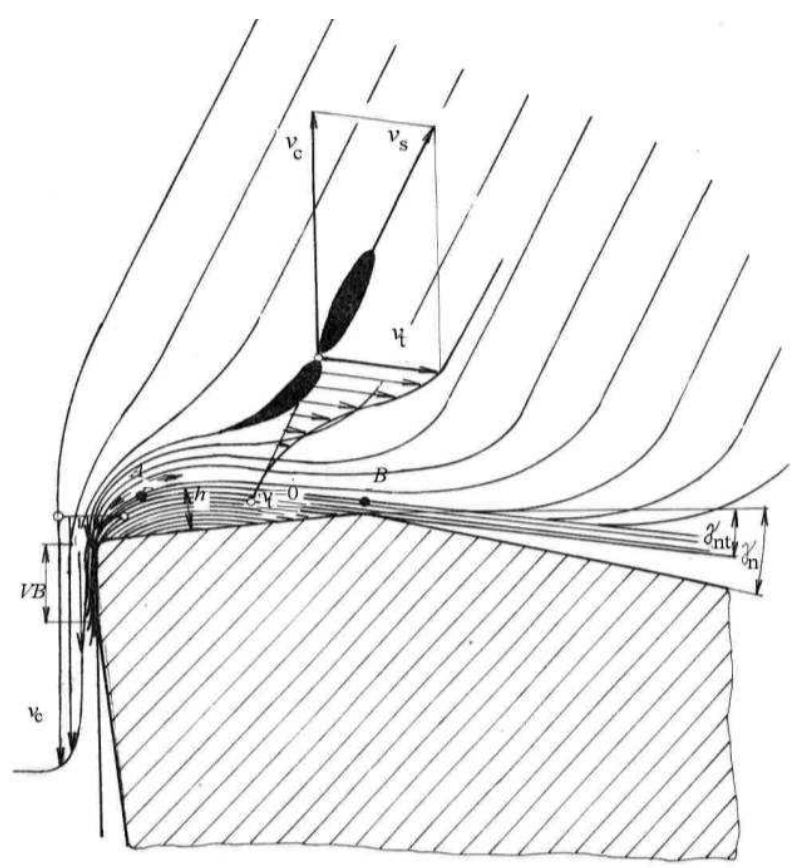

b)

Fig. 4 Metallographic thin section of the zone of chip formation. Material C45, $v_{c}=60 \mathrm{~m} \cdot \mathrm{min}^{-1}($ a) and scheme of chip formation with regulated field of plastic deformation (b)

As a result of strong adhesion of the delayed layer of the chip against the tool face, there occurs material flow along this layer. This fact can practically be used to increase the tool durability. When the cutting wedge is modified, retaining the delayed layer in required shape and size is possible. Corresponding model of chip formation is shown in Fig. 4.

Because the plastic zone is continually filled up with new material and does not grow in size, the question is where the material from this zone goes. Observation of the machining process, after its interruption, shows that along the cutting edge there leaves a stip of deformed metal in a form of secondary chip, formed by entrusion, In Fig. 5 there is a view of this process. Shortened tool face tab does not touch the workpiece and is protected by plastic secondary chip which moves along it.

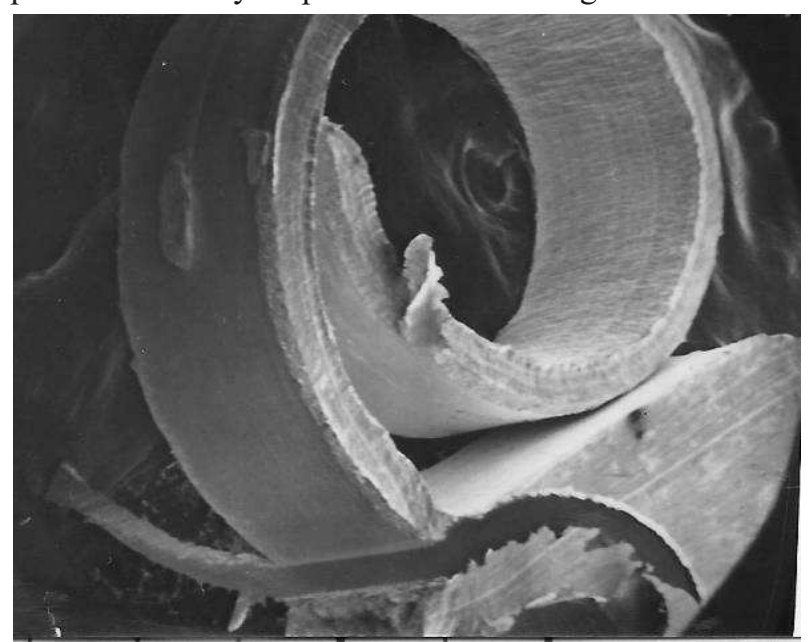

a)

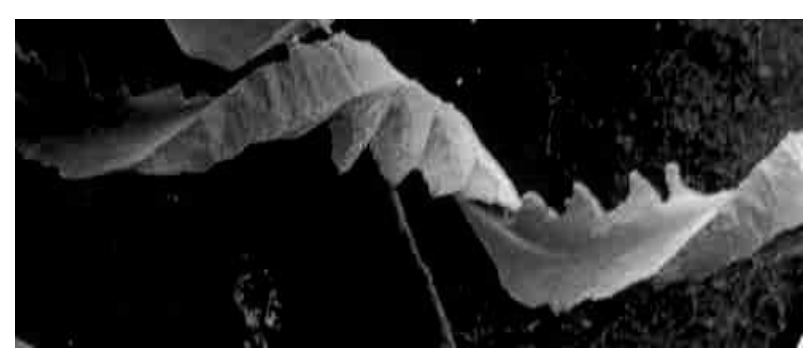

b)

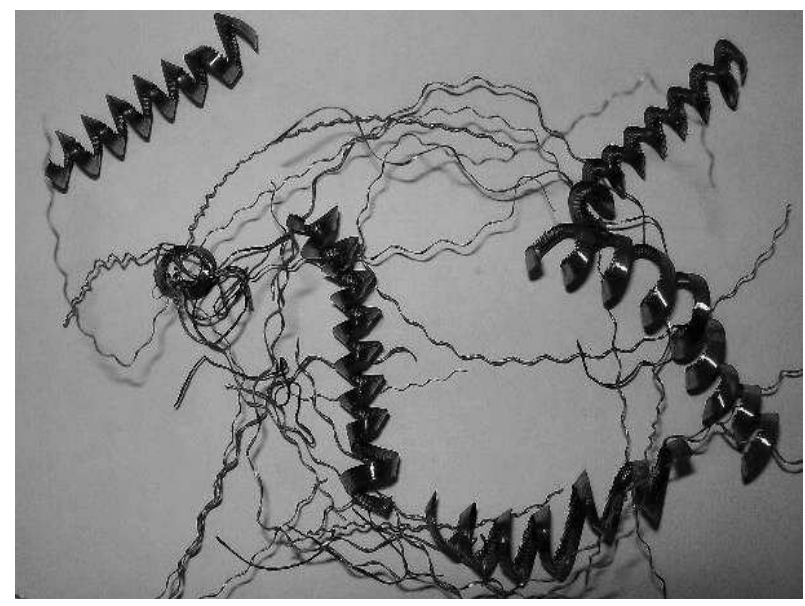

c)

Fig. 5 View of forming secondary chip when turning with a tool with shortened face - a, strip of secondary chip $-b$, photography of chips after turning $-c$

Metallographic observations of this strip have shown that in whole cross-cut section it is extremely deformed and has a fibre-like structure [15]. Its characteristics and possible use deserves further study. Tool wear occurs only on the back surface and less intensively than with classical tools because the layer of the plastic metal, according to Fig. 4, exceeds the cutting edge and partially of completely prevents the contact of the tool back and machined surface.

From Fig. 4 it can be seen that the chip slides easily along the plastic zone, which is stable.

In the study of built-up edge phenomena and the mechanism of plastic deformation during chip formation, it has appeared that the plastic field can serve as a means of protection of the cutting tool against wear.

\section{Analysis of cutting forces}

The result of the presented modification is also the change of different elements of cutting forces. Therefore, tests at equivalent cutting conditions as mentioned above have been performed. The result of measuring is shown in Fig. 6.

A considerable decrease of all three elements of cutting forces follows the diagramme when turning with a modified tool. The deepest decrease is the one of the main force $F_{c}$. In Fig. 7 there is a visual representation of relative size of different elements of cutting forces when turning with a classical tool and a tool with shortened face. 


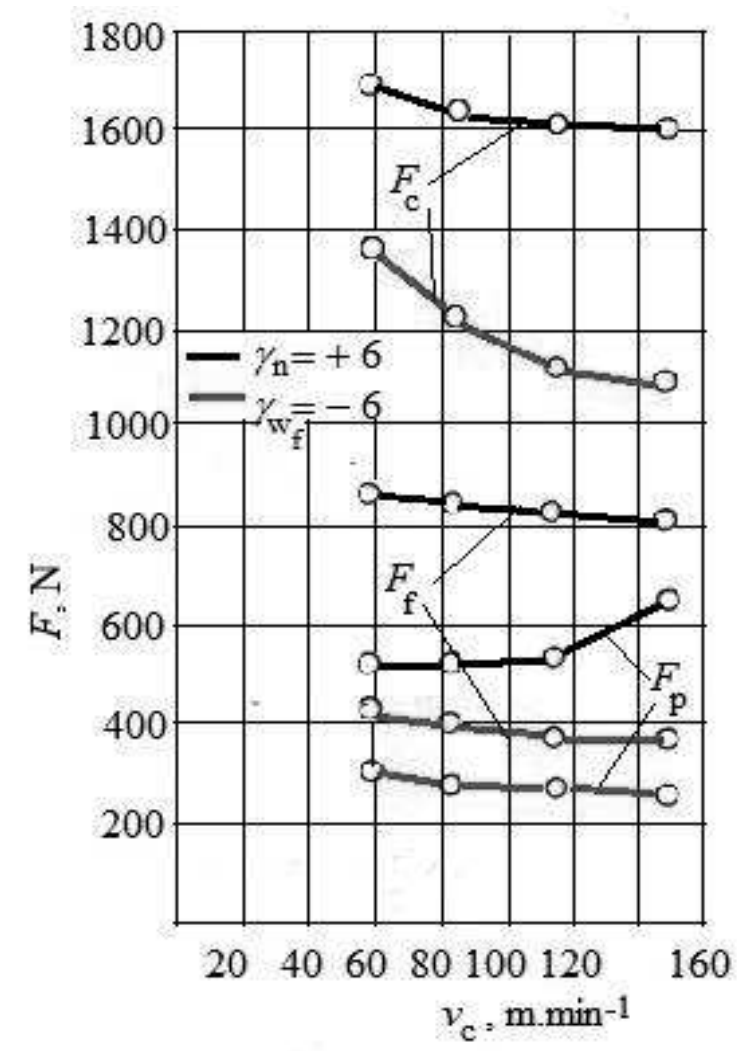

Fig. 6 Comparison of different elements of cutting forces during turning with a tool with regular and modified geometry of cutting wedge

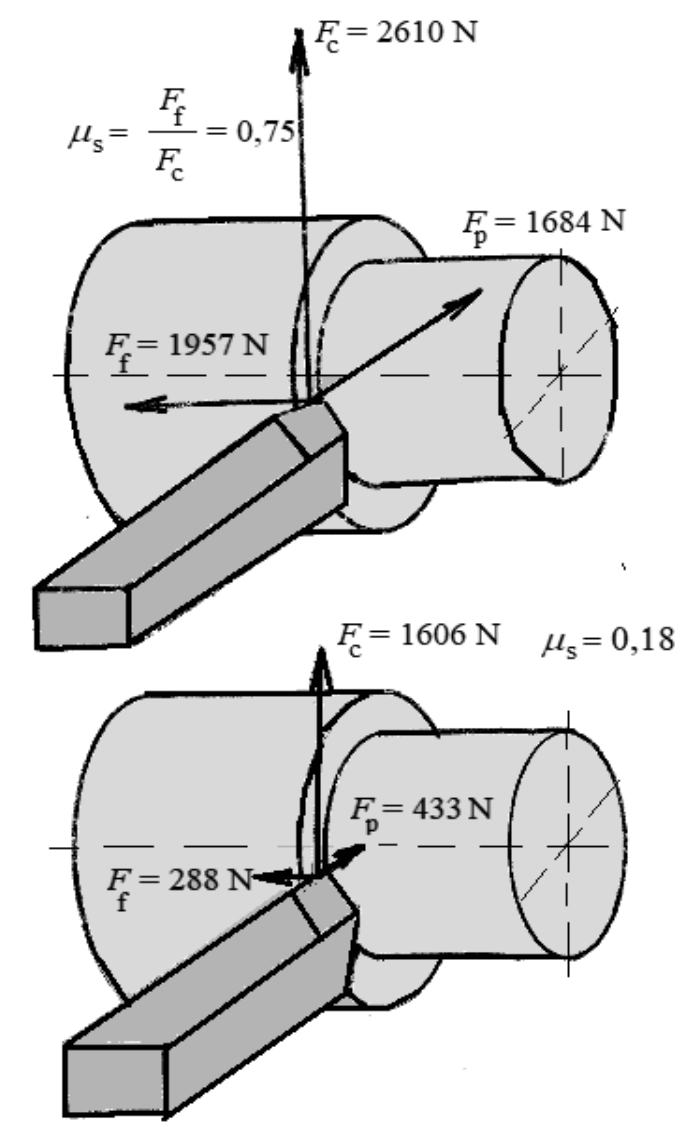

Fig. 7 Comparison of the size of cutting forces during turning with both tools at equivalent cutting conditions
If mean friction coefficient is defined as the ratio of friction (feed) and main cutting force, it can be seen that its value is, in case of shortened face, much smaller. It can be explained by shortening the area of contact of the chip with the face and its friction along the border of delayed zone, i.e. transfer from outer to internal friction inside the chip.

\section{Influence of tool modification on machining results}

As a result of strong adhesion of the delayed layer of the chip against the tool face, there occurs material flow along the plastic layer. This fact can practically be utilised in the increase of tool durability. When the cutting wedge is modified suitably, it is possible to obtain sustaining of delayed layer in required shape and size. It can realistically be supposed that when the face angle is sufficient $\gamma_{\mathrm{n} 2}>\gamma_{\mathrm{nt}}$ (Fig. 4b), the chip would slide along the plastic layer and there would be no contact of it with the tool face. Next it can be supposed that the width of shortened face tab, i.e. also plastic field inside the chip $w_{f}$ would approximately equal the thickness of the cut-off layer $h$. To prove those facts a range of experiments with such modified tools has been performed. In diagramme in Fig. 8 there is experimental dependence $V B$ on $\tau_{\mathrm{s}}$ obtained when turning with tools made of high-speed steel with different width $w_{f}$.

It can be seen that the width of shortened face tab has large influence on durability, on shortened tab there is plastic layer of different size formed, which protects the cutting wedge from wear. In cas in case $w_{f}=0.45 \mathrm{~mm}$, the tool works as a classical one with negative face angle, so it has small durability (at $V B_{k}=0.3 \mathrm{~mm}$ there is $T=20 \mathrm{~min}$ ). Optimal value of $w_{f}$ is around $0.3 \mathrm{~mm}$, which means it is close to the feed which has been used. At this value the durability is the best ( $T=180-190 \mathrm{~min})$. For the tool with shortened tab with the width $0.2 \mathrm{~mm}$, the fibre layer on the face does not have a sufficient size to protect the tool from wear.

From the diagramme it can be read that there exists an „optimal“width of shortened tab of the tool which is in the presented case cca $0.3 \mathrm{~mm}$, i.e. equals the used tool feed. At $w_{f}=0.2 \mathrm{~mm}$ there is still contact between the chip and the tool face. Vice versa, at larger widths $(0.4 \mathrm{~mm})$, the tool works as a one with negative face angle, with full direct contact of the chip with the face.

Tests to obtain dependence of tool durability on cutting speed have been performed. In Fig. 9 there is an experimental diagramme of dependence $T=\mathrm{f}\left(v_{\mathrm{c}}\right)$, obtained by long-term turning by classical and modified tools made of sintered carbid.

It can be seen in the diagramme that there has been and increase in tool durability in whole range of cutting speeds. This means that during turning, the plastic zone takes over the function of the cutting wedge. The increase of the durability is more considerable at cutting speeds within the range 40-80 m.min ${ }^{-1}$. Relatively smaller effect at cutting speeds up to $30 \mathrm{~m} \cdot \mathrm{min}^{-1}$ can be explained by the fact that a stable plastic zone is not formed on the modified cutting wedge. 


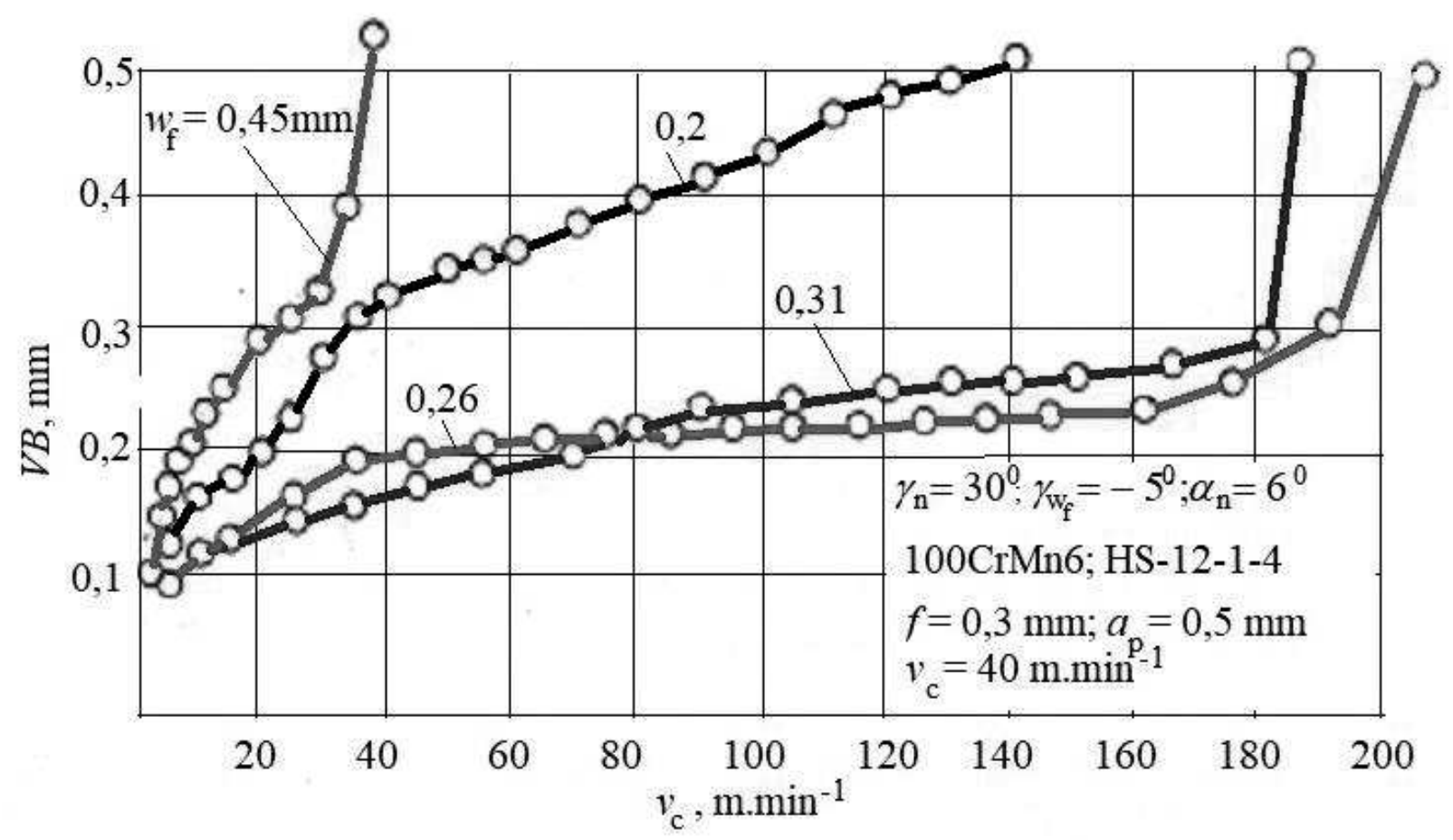

Fig. 8 Experimental dependence $V B=f\left(w_{f}\right)$ at different $w_{f}$

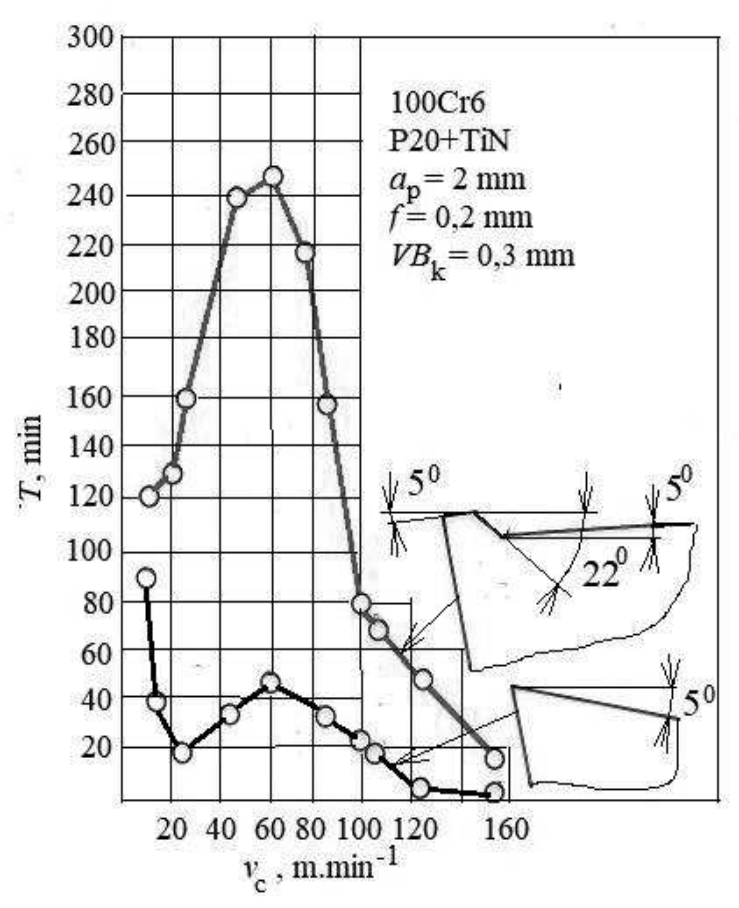

Fig. 9 Diagramme $T=f\left(v_{c}\right)$ obtained during turning with tools made of sintered carbid

During the experiment with extreme face angle (Fig. $10)$, no wear on the tool face or back has been recorded for a long time of turning. However, there has been a problem with chip formation. The chip has been firm, ribbon-shaped, and hard to shape, with small compression.

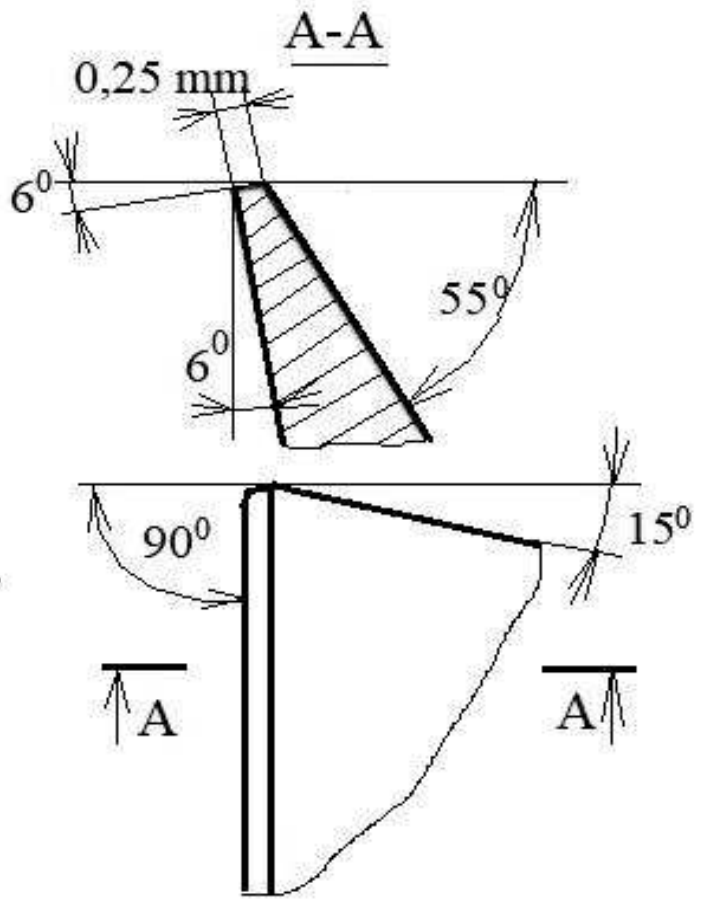

Fig. 10 Tool geometry with extreme face angle with shortened tab

\section{Quality of machined surface}

It can be supposed that this deformation mechanism would have positive effect on the quality of machined surface. In Fig. 11 there is an experimental diagramme of dependences $R_{Z}=\mathrm{f}\left(\mathrm{v}_{\mathrm{c}}\right)$, at width of shortened face $0.25 \mathrm{~mm}$ when turning steel $\mathrm{C} 45$. 


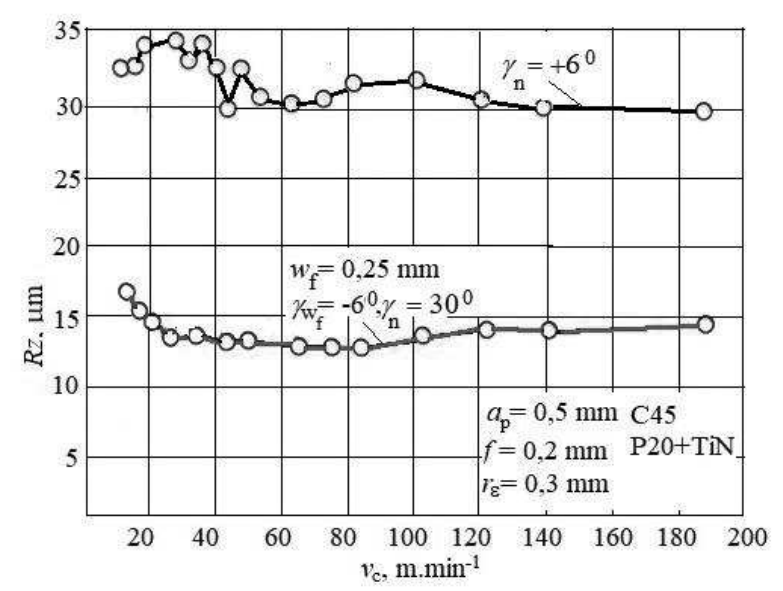

Fig. 11 Dependence of largest height of profile uneveness on cutting speed for classical and modified tool, obtained when turning workpiece with a tool made of

$$
\text { C45 }
$$

The improvement of the quality of machined surface is large. The mechanism of plastic deformation in front of shortened face tab might cause smoothing of the machined surface. The radius of ,plastic cutting edge"is much greater than the radius of tool cutting edge. Absolute values of $R_{Z}$ are half the value in comparison with a classical tool.

The course of dependence of $R_{Z}$ on feed seems interesting according to Fig. 12.

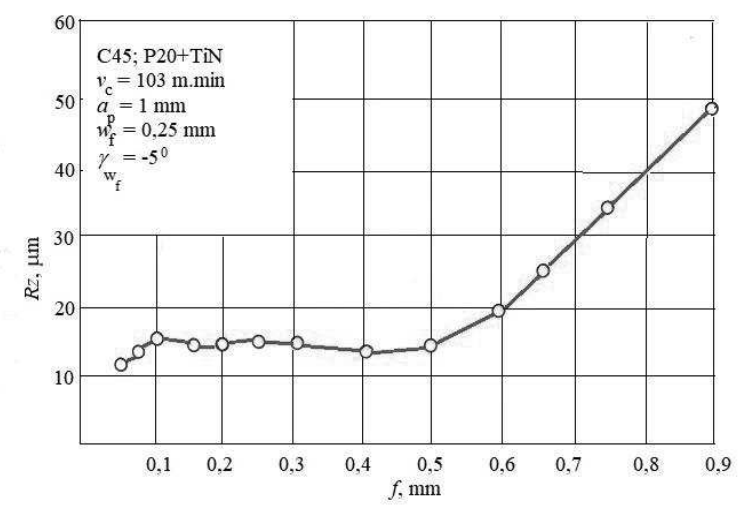

Fig. 12 Experimental dependence of the largest height of profile uneveness on feed when turning with a tool with shortened tab of contact, widht $0.25 \mathrm{~mm}$.

Because the width of the shortened face tab is in this case $0.25 \mathrm{~mm}$, at small feeds (up to $0.1 \mathrm{~mm}$ ) the tool works as a tool with negative face angle $-6^{0} . R_{Z}$ grows in concord with the theoretical laws. At feeds $0.1-0.5 \mathrm{~mm}$, the influence of plastic zone can be seen therefore the quality of machined surface does not depend on feed. Plastic „smoothing“of the surface occurs. After the feed exceeds $f=0.5 \mathrm{~mm}$, the tool works as a cla sical tool with positive face angle and phase (shortened face tab width is much smaller than feed). $R_{Z}$ grows according to the law of parabola.

It can be stated that to obtain the best results of machining, the width of shortened face tab should approximately equal feed.

To compare, there is an example of profilogramme of surface (Fig. 13) turned with a tool with straight and shortened face, at equivalent feed. It can be seen that the „plastic wedge“ deforms the tool profile, i.e. influences microgeometry of machined surface.

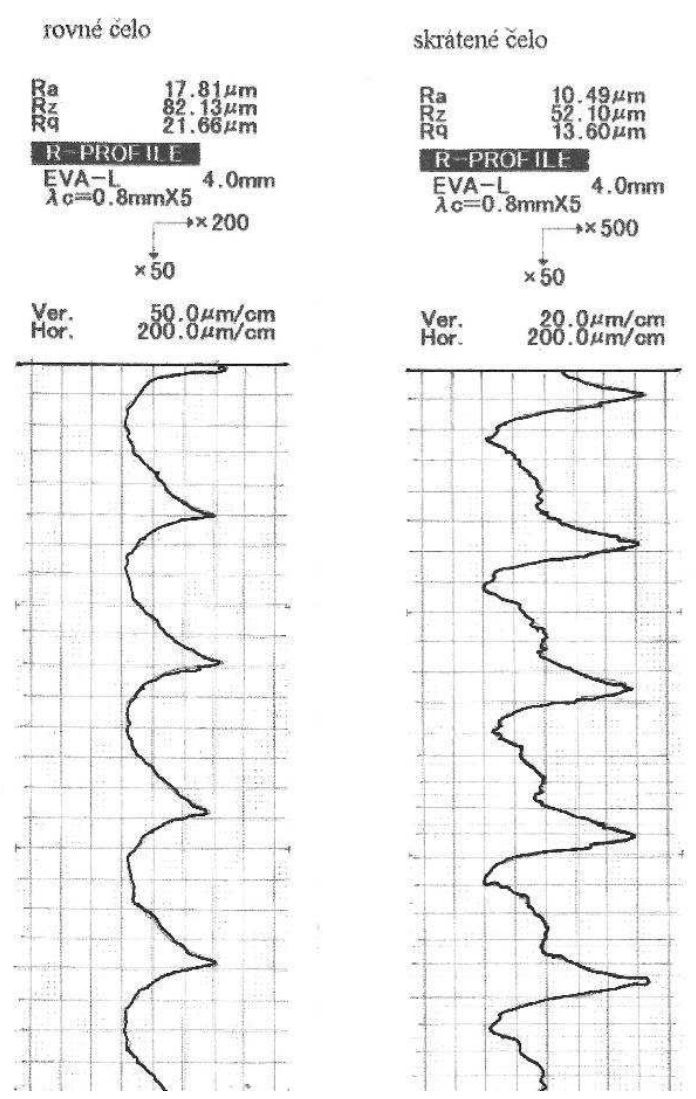

Fig. 13 Profile of surface, turned by tool with straight and shortened face. $f=0.48 \mathrm{~mm}$, workpiece: $C 45$; tool: P20

The effect of shortened face can be seen specifically when turning different materials. Tests of machining different materials with different mechanical characteristics have been performed.

In Fig. 14 there is an experimental dependence $R_{Z}$ obtained when turning aluminium alloy.

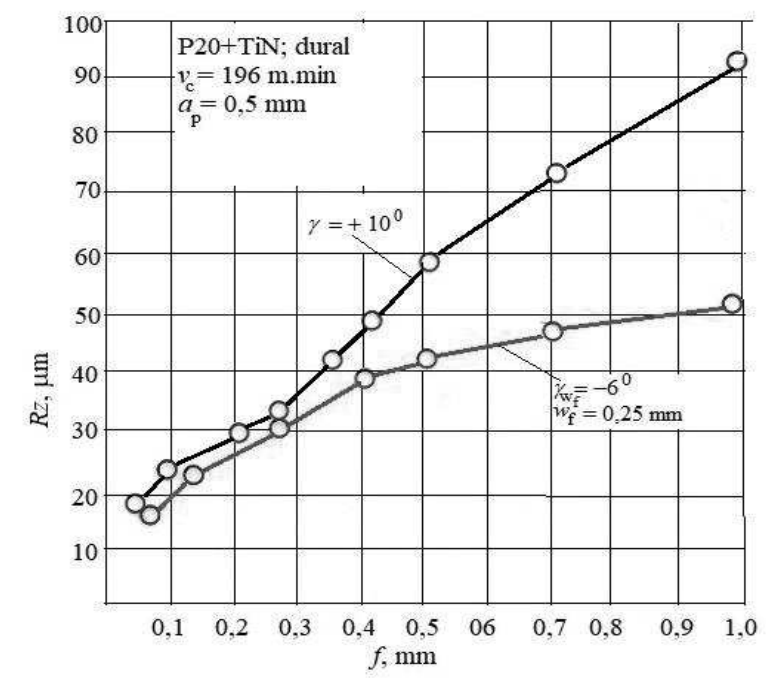

Fig. 14 Experimental dependence $R_{Z}$ on $f$ when turning aluminium alloy (dural) 
It can be seen that in the first case, there occurs copying of the shape of the cutting wedge into the machined surface. At shortened face, the surface is modified by plastic zone, which exceeds over the cutting wedge and plastically „smooths“ the workpiece surface.

Aluminium is characterised by formation of extreme built-up edges (pasters) on tool face. Up to feed $0.3 \mathrm{~mm}$, no difference in quality of machined surface can be observed because the tool with shortened face works as a tool with negative face angle. When this feed is exceeded (larger than the surface of shortened face), limiting of the width of built-up edge is shown in shortened tab, by which it always takes over the same size. It means the quality of machined surface increases greatly towards higher feeds.

An interesting course of dependence can be observed when turning titanium alloy (Fig. 15).

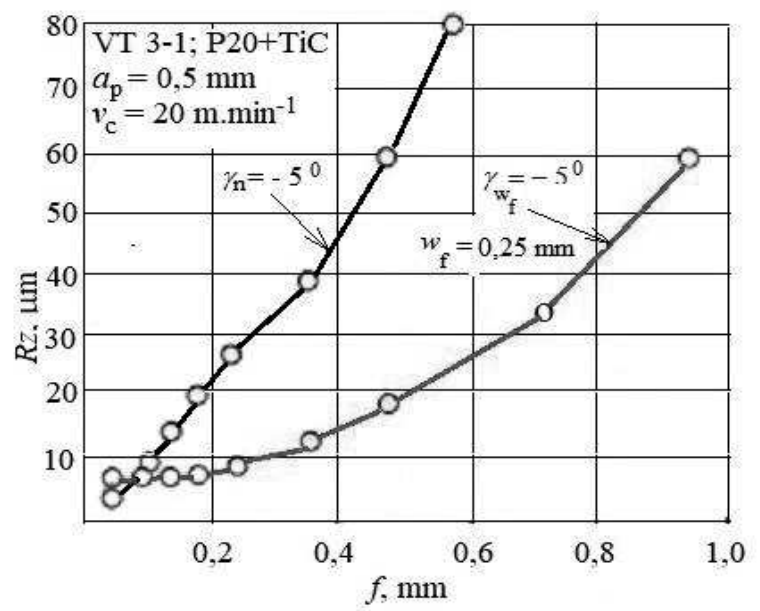

Fig. 15 Experimental dependence $R_{Z}$ on $f$ when turning titanium alloy

It is a well-known fact that the area of contact of the chip with tool face is much smaller when turning titanium than steel. This is the reason why up to feed $0.1 \mathrm{~mm}$, the values of $R_{Z}$ are approximately the same. Limiting the contact of the chip and the face occurs after exceeding this value. The effect of decreasing $R_{Z}$ grows towards higher feed values. Titanium, as it is known, belongs among hard machinable materials mainly due to its extreme friction coefficient with other metals.

\section{Conclusion}

Influencing of mechanism of plastic deformation of cut material in front of tool cutting wedge can secure considerably smaller tool wear and improvement of the quality of machined surface. Secondarily, those considerations about if it is necessary to apply tools highly resistent to wear because there is no direct contact of the cutting tool and the workpiece can be taken. It is preferred for the tool material to have adhesion ability towards cut material and good heat conductivity. For coated tool, the coat should have those characteristics.

\section{Acknowledgement}

The article hassupported by project APPV-18-0316.

\section{References}

[1] DMOCHOVSKI, J. (1978) Podstavy obróbki skawaniem. Warszawa, 1978, $586 \mathrm{~s}$.

[2] HOLEŠOVSKÝ, F. (1991) Materiály a technologie obrábění. Ústí nad Labem, UJEP, 1991, $250 \mathrm{~s}$.

[3] TRENDT. M. (1991) Metal Cutting. London Boston, : Ed. Oxford, Butterworths - Helnemann, 1991, 236 s., ISBN 0-7506-1068-9

[4] BUDA, J. BÉKÉS, J. (1967) Teoretické základy obrábania kovov. Bratislava: ALFA, 1967, 392s.

[5] HOSHI, K.HOSHI, T. (1969) On the metal cutting mechanism with the built- up-edge. Mem. Fac. Engng. Hokaido University 12, Nr. 3, 1969

[6] WEBER, T, N. () LOLADZE, T. N. (1986) Grundlagen des Spanens. Berlin: VEB Verlag Technik, 1986, $255 \mathrm{~s}$.

[7] MÁDL, J., KVASNIČKA, I. (1998) Optimalizace obráběcího procesu. Praha: ČVUT, 1998, 168 s.

[8] P̌̌IKRYL, Z., MUSÍLKOVÁ, R. (1971) Teorie obrábění. Praha: SNTL, 1971, 198 s.

[9] BUDA, J., VASILKO, K. Metóda zastavenia procesu obrábania bez špeciálnych prípravkov. $\mathrm{Pa}$ tent SR 122243.

[10] KALPAKJIAN, S. (1989) Manufacturing Enineering and Technology. New York: AddisonWesley Publishing Company, 1989, 1199, ISBN 0-201-12849-7

[11] WORTHINGTON, B. (1974) Surface integrity, cutting forces and chip formation when machining with double rake angle tools. International Journal Mechanical Tool Design and Research, 1974, 14, No. 3, pp. 279-295.

[12] ŠERAK, J., VOJTECH, D. (2017) Dispersion of Mechanical Properties of CommencialAluminum Alloys within Their Material Standarts. Manufacturing Technology, 2017, Vol 17, Nr.5, pp. 831837.

[13] HOLEŠOVSKÝ, F., HRALA, M., NOVÁK, M. (2013) Ground Surface -Quality and its oading Capacity. Manufacturing Technology, 2013, Vol. 3, pp. 26-32, ISSN 1213-2489.

[14] JERSAK, J et al. (2017) The integrity of the Surface after Milling of Bearing Steel. Manufacturing Technology, 2017, No. 4, pp. 13-20, ISSN 12132489.

[15] VASILKO, K., ŠLESÁR, M. Sústružnícky nůž. . Patent SR č. 262642. 